\title{
La Doping of CdS for Enhanced CdS/CdSe Quantum Dot Cosensitized Solar Cells
}

\author{
Xiaolei Qi, Xiaoping Zou, and Sheng He \\ Research Center for Sensor Technology, Beijing Key Laboratory for Sensor, Ministry of Education Key Laboratory for \\ Modern Measurement and Control Technology, School of Applied Sciences, and School of Instrumentation Science and \\ Optoelectronics Engineering, Beijing Information Science and Technology University, Jianxiangqiao Campus, Beijing 100101, China
}

Correspondence should be addressed to Xiaoping Zou; xpzou2005@gmail.com

Received 4 June 2014; Revised 6 September 2014; Accepted 8 September 2014

Academic Editor: Steen Skaarup

Copyright (C) 2015 Xiaolei Qi et al. This is an open access article distributed under the Creative Commons Attribution License, which permits unrestricted use, distribution, and reproduction in any medium, provided the original work is properly cited.

CdS/CdSe system of quantum dot cosensitized solar cells (QDCSCs) is one of the most attractive structures for high-efficiency due to its effect of level adjusting. However, the stepwise structure formed between levels of CdS and CdSe has a limitation for enhancing the efficiencies. Metal ions doping in quantum dots have emerged as a common way for changing the Fermi level, band gap, and conductance. Here we report an innovative concept for the rare earth materials La-doped of the CdS layer in the CdS/CdSe QDCSCs by means of the successive ionic layer adsorption and reaction (SILAR). Then we tested that La doped quantum dots can help more electrons accumulate in CdS film, which makes the Fermi level shift up and form a stepped structure. This method leads to enhanced absorption intensity, obviously increasing current density in CdS/CdSe QDCSCs. Our research is a new exploration for improving efficiencies of quantum dot sensitized solar cells.

\section{Introduction}

Emerging new technology of metal ions doping in quantum dots (QDs) has the potential to improve photoelectric conversion efficiency (PCE) of solar cells for the change of Fermi level, band gap, and conductance [1]. Based on this technology, transition metal ion dopant, which has optical activity, such as $\mathrm{Mn}^{2+}$, can change the electronic and optical properties of QDs. Moreover, dopants in the area of middle band gaps of QDs generate electronic states and transform the dynamics of charge separation and recombination. The photoelectric characteristics of semiconductor nanocrystals can also be adjusted by controlling the type and concentration of dopants. In 2008, Lee et al. prepared CdSe and Mg-doped CdSe quantum dots cosensitized solar cells. And compared with the pure CdSe quantum dots sensitized solar cells under the same conditions, the short circuit current of the doped one improved by $47 \%$ [2]. In 2013, Lee et al. report on a $\mathrm{Hg}$ doping of $\mathrm{PbS}$ quantum dots sensitized solar cell with an unprecedentedly high current density of $30 \mathrm{~mA} / \mathrm{cm}^{2}$. They also obtained a power conversion efficiency of $5.6 \%$ at one sun illumination due to the extremely high current density
[3]. Huang et al. of our group studied the properties of $\mathrm{Cu}$-doped-PbS/CdS QDCSCs by changing the doping ratio of $\mathrm{Cu}^{2+}$ and discovered that the ability to capture incident photons of $\mathrm{PbS}$ was improved after $\mathrm{Cu}$ doping [4]. In contrast to the undoped solar cells, the doped one achieved a high conversion efficiency $(2.01 \%)$ and a remarkable short circuit current density $\left(21 \mathrm{~mA} / \mathrm{cm}^{2}\right)$. Li et al. prepared Cu-dopedCdS/In-doped-CdS quantum dot solar cells by using double doped quantum dot sensitizer, which formed a stepwise structure [5]. The structure was propitious to the electron delivery and collection and led to an improved efficiency. The application of rare earth materials doping in dye sensitized solar cells is a new exploration. Up and down conversion luminescence caused by doping with rare earth ions can enhance the optical trapping and photocurrent in solar cells by expanding the absorption band from visible spectrum to UV infrared region; moreover, the doping effect of rare earth ions raises Fermi level of photoanode, improves photovoltage of cells, and leads to an increased PCE [6-10]. However, up to now, this exploration which has great significance is rare to see. More recently, Wu et al. doped the photoanode of 
TABLE 1: Experiment parameters and sample calibration of different doping concentrations of La doped CdS.

\begin{tabular}{lcccccc}
\hline Samples & Doping concentration $(\mathrm{La}: \mathrm{Cd})$ & Total SILAR cycles & $J_{\text {SC }}\left(\mathrm{mA} / \mathrm{cm}^{2}\right)$ & $V_{\mathrm{OC}}(\mathrm{V})$ & $\mathrm{FF}$ & $\eta(\%)$ \\
\hline M-0 & 0 & $4+4$ & 3.88 & 0.42 & 0.34 & 0.54 \\
M-10 & $1: 10$ & $4+4$ & 5.20 & 0.43 & 0.29 & 0.66 \\
M-50 & $1: 50$ & $4+4$ & 5.80 & 0.43 & 0.27 \\
M-100 & $1: 100$ & $4+4$ & 5.79 & 0.69 \\
M-200 & $1: 200$ & $4+4$ & 5.65 & 0.42 & 0.26 & 0.66 \\
\hline
\end{tabular}

dye sensitized solar cells with rare earth fluoride $\left(\mathrm{YF}_{3}: \mathrm{Eu}^{3+}\right)$ dopants [11]. This method has significantly increased the PCE of solar cells for dual function of rare earth compounds which includes conversion luminescence and doping effect. In contrast to the undoped system, the PCE of doped solar cells has enhanced $35 \%$.

$\mathrm{CdS} / \mathrm{CdSe}$ system is one of the most popular structures in research field and one of the most efficient QDSCs systems due to the effect of adjusting level. For example, Santra and Kamat employed the CdS/CdSe structure and deposited Mn-doped-CdS/CdSe on mesoporous $\mathrm{TiO}_{2}$ film as the photoanode preparing the QDCSCs, which led to record the standard light intensity short circuit current of $20.7 \mathrm{~mA} / \mathrm{cm}^{2}$ and PCE of 5.42\% [12]. In the present study, our work was all based on this system. Inspired by the rare earth fluoride doping the photoanode of dye sensitized solar cells, we employed lanthanum (La) doped CdS methodology and assembled the La doping of CdS/CdSe quantum dot cosensitized solar cells which was the first case. Then we analyzed the mechanism about the influences of La dopant on cells by representing photoanode materials and testing performances of solar cells.

\section{Experimental}

2.1. Preparation of La-Doped-CdS/CdSe Cosensitized Mesoporous $\mathrm{TiO}_{2}$ Photoanode. In our experiment, deposition process of CdS: $\mathrm{La} Q \mathrm{QDs}$ on nanostructured $\mathrm{TiO}_{2}$ surface used the SILAR method. First, $0.1 \mathrm{M} \mathrm{Cd}\left(\mathrm{NO}_{3}\right)_{2} \cdot 4 \mathrm{H}_{2} \mathrm{O}$ was dissolved in ethanol using ultrasonic bath for $45 \mathrm{~min}$. Then, $\mathrm{LaCl}_{3}$ was added to the $\mathrm{Cd}\left(\mathrm{NO}_{3}\right)_{2}$ ethanol solution with corresponding concentration as cation source. Different doping ratios of $\mathrm{La}^{3+}: \mathrm{Cd}^{2+}(1: 10,1: 50,1: 100,1: 200$, and undoped) were chosen to compare with each other. $\mathrm{Na}_{2} \mathrm{~S}$ $(0.1 \mathrm{M})$ was dissolved in methanol as anion source. The FTO glass electrode was precoated with transparent active $\mathrm{TiO}_{2}$ layers, which formed a wide band gap semiconductor $\mathrm{TiO}_{2}$ photoanode. Next, we performed the SILAR cycle procedure. The $\mathrm{TiO}_{2}$ photoanode was firstly dipped into metal cation solution for $5 \mathrm{~min}$, rinsed with ethanol, and dried with $\mathrm{N}_{2}$ and then dipped into sulfide anion solution for $5 \mathrm{~min}$, rinsed again with methanol, and dried with $\mathrm{N}_{2}$. Specifically, the anion source was prepared by dissolving $\mathrm{Na}_{2} \mathrm{SO}_{3}(0.12 \mathrm{M})$, Se $(0.06 \mathrm{M})$, and a little permutite in deionized water, then refluxing in aqueous condition at $70^{\circ} \mathrm{C}$ for about 7 hours, and finally filtering out the unreacted $\mathrm{Se}$ and permutite [13]. The SILAR processes of CdSe were similar to those of CdS: La QDs. The $\mathrm{TiO}_{2} / \mathrm{CdS}$ : La photoanode was successively immersed in metal cation $\left(\mathrm{Cd}^{2+}\right)$ and anion $\left(\mathrm{Se}^{2+}\right)$ solutions, then rinsed with corresponding solvent, and dried. Finally, the preparation of La-doped-CdS/CdSe cosensitized mesoporous $\mathrm{TiO}_{2}$ photoanode was finished.

2.2. Fabrication of QDCSCs. $\mathrm{Na}_{2} \mathrm{~S}(1 \mathrm{M})$ and $\mathrm{S}(1 \mathrm{M})$ were dissolved in deionized water as polysulfide electrolyte. $\mathrm{Pt}$ counter electrodes were used in our solar cells. Then the Ladoped-CdS/CdSe cosensitized $\mathrm{TiO}_{2}$ photoanode, polysulfide electrolyte, and Pt counter electrode were assembled simply. The packaged solar cells should be put for about $40 \mathrm{~min}$ and avoid light processing. Then we can perform the testing.

\section{Results and Discussion}

3.1. Influence of Doping Concentration on Solar Cell Performance. We have investigated the effect of diverse doping density on properties of La-doped-CdS/CdSe QDCSCs. The specific experiment parameter and sample calibration used are shown in Table 1, among which M-0 represents doping density of La to be zero, namely, undoped, and M-10 represents a 1:10 relationship between molarity of La and Cd. And $4+4$ represents the total SILAR cycles that four layers of La-doped CdS are deposited firstly, followed by deposition of four layers of CdSe.

Figure 1 shows the $J-V$ curves of a range of QDCSCs with samples of diverse doping density from M-0 to M-200. Table 1 shows the specific parameters of solar cells corresponding to Figure 1. In contrast to undoped cell performance, all the doped solar cell parameters are improved a lot, especially the current density. It is easy to get the regularity from Table 1 that current density increases with the reducing La doping ratio then decreases. When La doping ratio is $1: 50$, current density achieves the maximal value $\left(J_{\mathrm{SC}}=5.80 \mathrm{~mA} / \mathrm{cm}^{2}\right)$; however, open-circuit voltage and fill factor reduce a little. When doping ratio is $1: 10$ or $1: 50$, open-circuit voltage reaches the $\max \left(V_{\mathrm{OC}}=430 \mathrm{mV}\right)$. And the fill factor of ratio $(1: 10)$ is much larger $(\mathrm{FF}=0.29)$ than the ratio of $1: 50$. All things considered, when the La doping ratio is $1: 50$, solar cell efficiency reaches the maximum $(\eta=0.69 \%)$.

3.2. Influence of Thickness of Doped CdS on Solar Cell Performance. We have investigated the effect of different SILAR cycles on properties of La-doped-CdS/CdSe QDCSCs based on the optimal doping ratio mentioned in preamble. In this experiment, the doping proportion was chosen as 1:50. Furthermore, detailed experiment parameters and sample calibration used are shown in Table 2. Then we assembled a range of QDCSCs with samples of different SILAR cycles from S-4 to S-10 and measured the $J-V$ curves and specific 
TABLE 2: Experiment parameters and sample calibration of different SILAR cycles of La doped CdS.

\begin{tabular}{lcccccc}
\hline Samples & Doping concentration $(\mathrm{La}: \mathrm{Cd})$ & Total SILAR cycles & $J_{\text {SC }}\left(\mathrm{mA} / \mathrm{cm}^{2}\right)$ & $V_{\text {OC }}(\mathrm{V})$ & $\mathrm{FF}$ & $\eta(\%)$ \\
\hline S-4 & $1: 50$ & $4+4$ & 5.92 & 6.41 & 0.21 & 0.52 \\
S-6 & $1: 50$ & $6+4$ & 6.97 & 0.40 & 0.25 \\
S-8 & $1: 50$ & $8+4$ & 5.58 & 0.72 & 0.21 \\
S-10 & $1: 50$ & $10+4$ & 0.37 & 0.53 \\
\hline
\end{tabular}

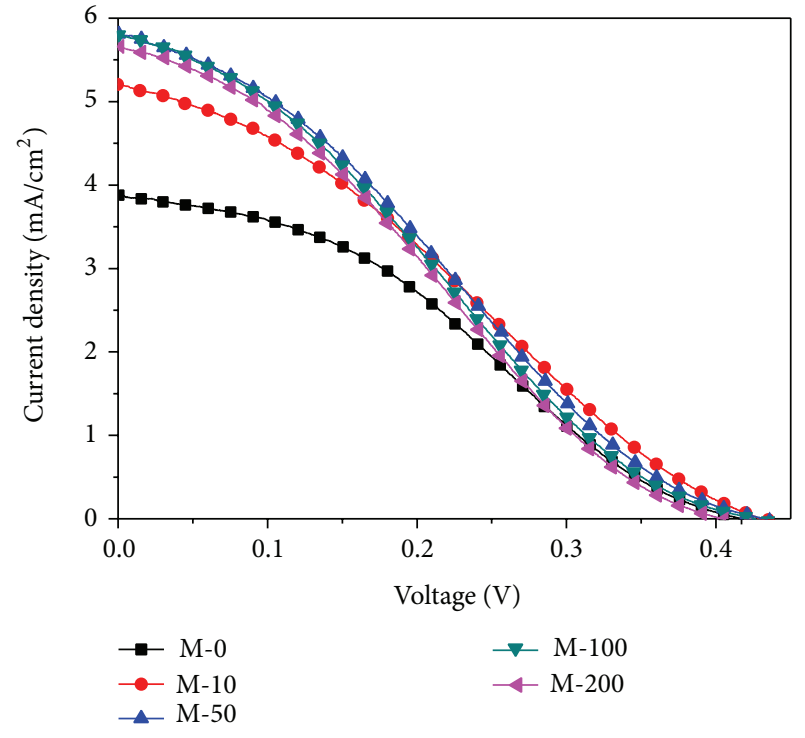

FIGURE 1: The $J-V$ curves of different working electrodes based on La-doped CdS. The corresponding parameters are of M-0, M-10, M50, M-100, and M-200.

parameters of solar cells, respectively (Figure 2 and Table 2). From Table 2, we can find the tendency that, with SILAR cycles of La-doped CdS increasing, current density and fill factor first rise and then decrease. When the SILAR cycles are 6 , they all reach the peak value, which are $6.97 \mathrm{~mA} / \mathrm{cm}^{2}$ and 0.25 . At first, quantum dots increase with the SILAR cycles adding, which can promote generation of photoinduced carriers and consequently lead to current density raising. When the SILAR cycles keep adding, La-CdS layer thickens which makes the transportation path of electrons get longer and increases the electrons loss and finally reduces the current density. However, the open-circuit voltage is ever decreasing, and it achieves the maximal voltage value $(0.41 \mathrm{~V})$ as SILAR cycles are 4 . On the whole, when the SILAR cycles of La-doped CdS are 6, we attain the highest solar cell efficiency (0.70\%).

Compared with the aforementioned results of different doping concentrations of La-doped CdS, we can find that current density of this experiment enhances slightly, but the open-circuit voltage and fill factor have a greater reduction. As a result, it finally leads to a very small increase in cell efficiency. The voltage reduction is mainly because we have changed the $\mathrm{TiO}_{2}$ slurry and screen used in silkscreen printing in the latter experiments. It results in $\mathrm{TiO}_{2}$ films painted a little thinner than the previous films and a relatively poor uniformity. The fill factor reduction is related

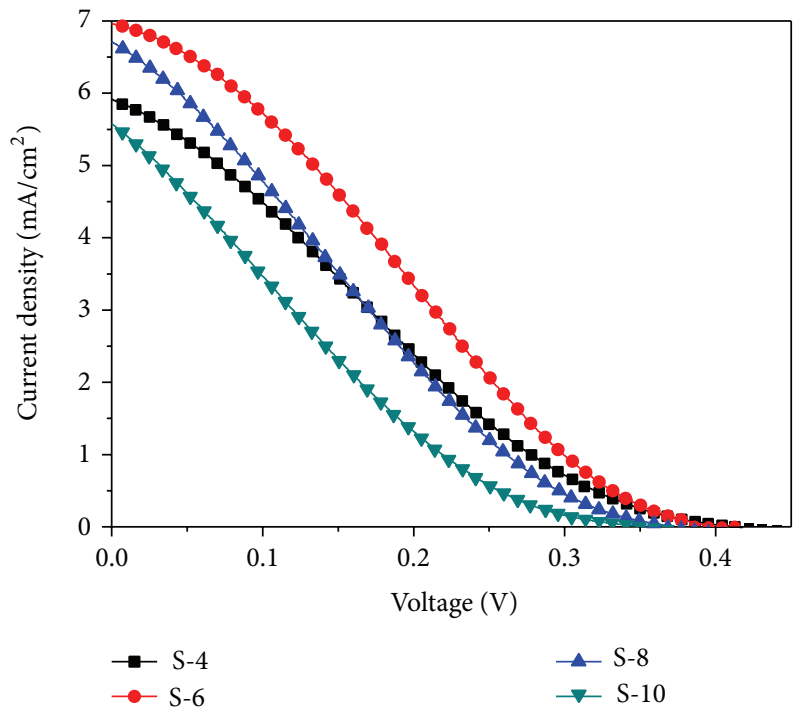

FIgURE 2: The $J-V$ curves of different working electrodes based on La-doped CdS. The corresponding parameters are of S-4, S-6, S-8, and S-10.

to fabrication of Pt counter electrode. Pt slutty painted too little and counter electrode put too long will affect the fill factor.

3.3. Mechanism Analysis of La-Doped QDCSCs. First, we performed the materials characterization of La-dopedCdS/CdSe photoanode. Figure 3 shows the SEM image of (a) photoanode; we can see the morphology of $\mathrm{TiO}_{2}$ particles about $20 \mathrm{~nm}$ size of scale. But it is difficult to observe the morphology of quantum dots by SEM image. Then we performed the characterization of TEM (Figure 4). Figure 3(b) shows the EDS energy spectrum diagram of photoanode. We cannot find La element; it is because the La-doped ratio is $1: 50$ that the amount of dopant $\mathrm{La}$ is too little to detect the characteristic X-ray of La element by instrument. So we used the inductively coupled plasma emission spectrometer (ICPOES) to perform a further qualitative and quantitative analysis of doped elements (shown in Table 3). In this experiment, La doping ratio is 1:50; namely, molar concentration of $\mathrm{La}$ is 0.02 times molar concentration of $\mathrm{Cd}^{2+}$ in precursor solution $\left(\mathrm{Cd}^{2+}\right.$ solution). Through the analysis of ICP-OES, we know the actual molar ratio of $\mathrm{La}: \mathrm{Cd}$ in La-doped-CdS/CdSe photoanode is 1:400; namely, the molar concentration of La is 0.0025 times molar concentration of $\mathrm{Cd}^{2+}$ which is only $12.5 \%$ of the doping ratio we expected. This result shows that very little of La has doped in CdS. 


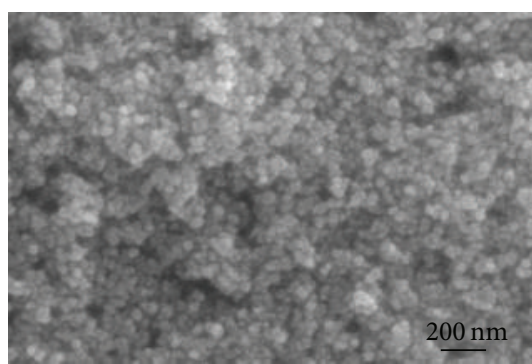

(a)

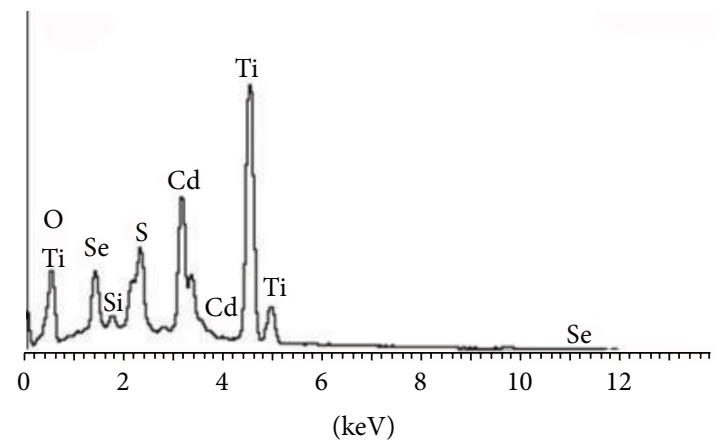

(b)

FIGURE 3: SEM image of photoanode and corresponding EDS energy spectrum diagram: (a) SEM image and (b) EDS energy spectrum.

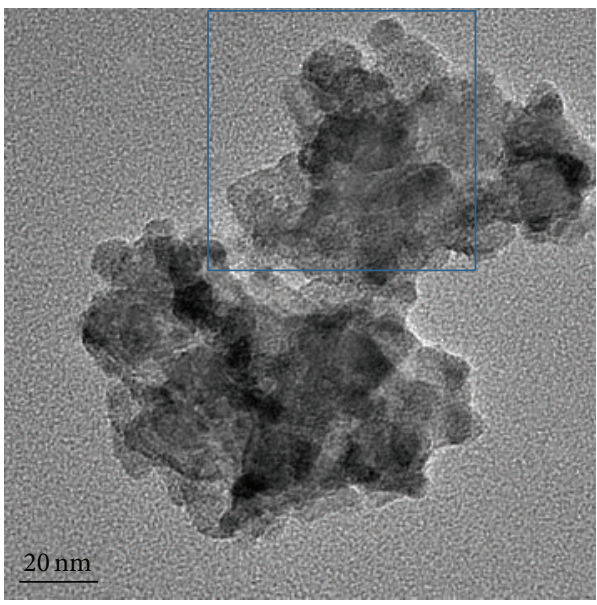

(a)

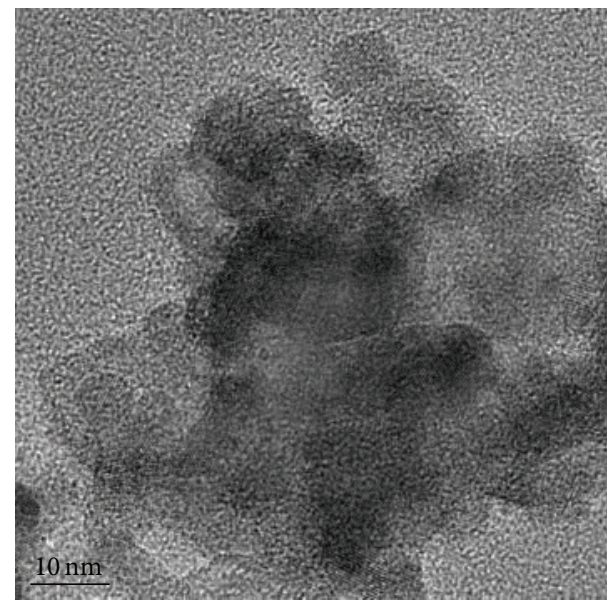

(b)

FIgure 4: The TEM images of La-doped-CdS/CdSe films: (a) low magnification figure and (b) high magnification figure.

Figure 4 shows the TEM micrograph of (a) low magnification figure of photoanode and (b) high magnification figure of rectangular box part which is in (a). We can see nanoparticles about 5-20 nm in Figure 4(a). Observing the high magnification figure we can find that the large particles are $\mathrm{TiO}_{2}$ nanoparticles, and the small particles are La-doped quantum dot sensitizers. The size of small particles is about $5 \mathrm{~nm}$.

Figure 5 shows the XRD figure of La-doped-CdS/CdSe photoanode. After the deposition of La-doped-CdS and CdSe in photoanode, we can see the diffraction peak of La dopants, in addition to the existing diffraction peak of $\mathrm{FTO}, \mathrm{TiO}_{2}, \mathrm{CdS}$, and CdSe. When $2 \theta$ value is about $47.6^{\circ}$, it is corresponding to the (332) crystal face of $\mathrm{La}_{2} \mathrm{Se}_{3}$. Hence, it proves that $\mathrm{La}$ dopants really have doped in the photoanode.

The effect of rare earth materials doping on the optoelectronic properties of the CdS/CdSe is studied by comparing the ultraviolet-visible absorption spectrum of Ladoped-CdS(4)/CdSe(4) with that of $\mathrm{CdS}(4) / \mathrm{CdSe}(4)$ photoanodes, as shown in Figure 6. Because the band gap of CdS quantum dot becomes narrow (Figure 10) after doping CdS with La, which can finally enhance the absorption
TABLE 3: ICP-OES quantitative analysis of La-doped CdS. The doping ratio of $\mathrm{La}: \mathrm{Cd}$ is 1:50 in precursor solution. And the real doping ratio of $\mathrm{La}: \mathrm{Cd}$ is $1: 400$ which we measured in the table.

\begin{tabular}{lccc}
\hline Sample & $\mathrm{Cd}(\mu \mathrm{g})$ & $\mathrm{La}(\mu \mathrm{g})$ & $\mathrm{La}:$ Cd molar ratio \\
\hline La-CdS & 31.75 & 0.0982 & $1: 400$ \\
\hline
\end{tabular}

capacity of photoanodes. Compared with the pure CdS(4)/ $\mathrm{CdSe}(4)$ photoanode, the absorption strength of La-doped$\mathrm{CdS}(4) / \mathrm{CdSe}(4)$ photoanode is markedly improved within the wavelength of $350-525 \mathrm{~nm}$; this result is advantageous to improvement of current density of La-doped solar cells.

In Figure 6, we just showed the comparison of the absorption spectrum between $\mathrm{La}-\mathrm{CdS}(4) / \mathrm{CdSe}(4)$ and $\mathrm{CdS}(4) /$ $\mathrm{CdSe}(4)$ photoanodes. To compare the absorption ability definitely, we performed the UV-Vis absorption spectroscopy of La-CdS/CdSe photoanode of different SILAR cycles, which is shown in Figure 7. When SILAR cycles of La-doped CdS layers were added from 4 to 10 on the condition of fixed SILAR cycles of CdSe layers, the absorption capacity of photoanodes were also increased especially in wavelength of $350-500 \mathrm{~nm}$. 


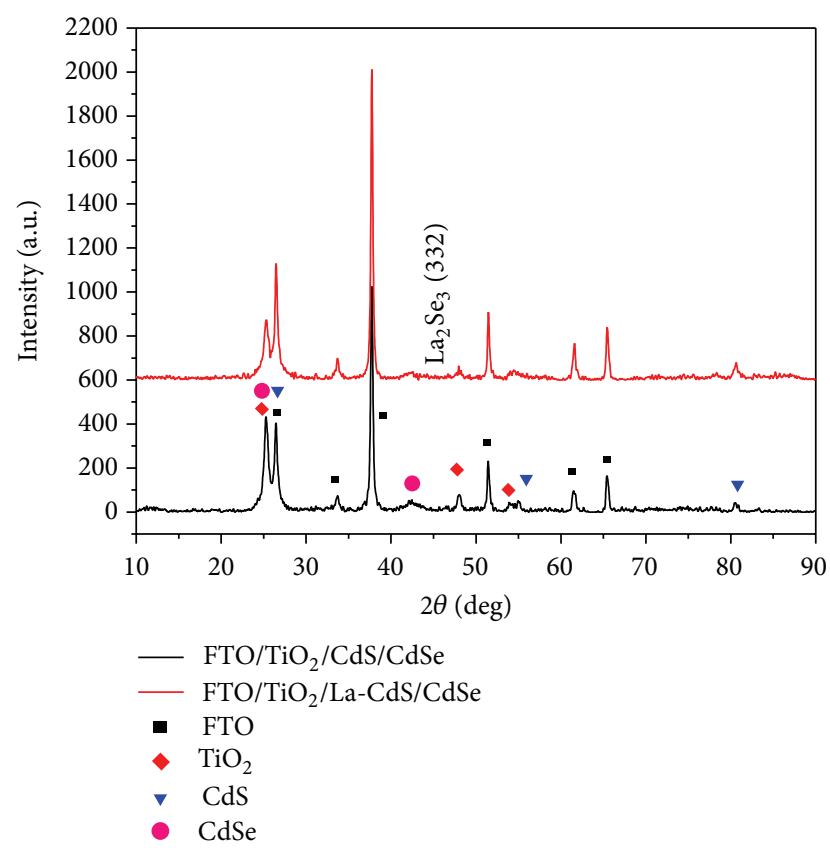

Figure 5: The XRD patterns of La-doped-CdS/CdSe films.

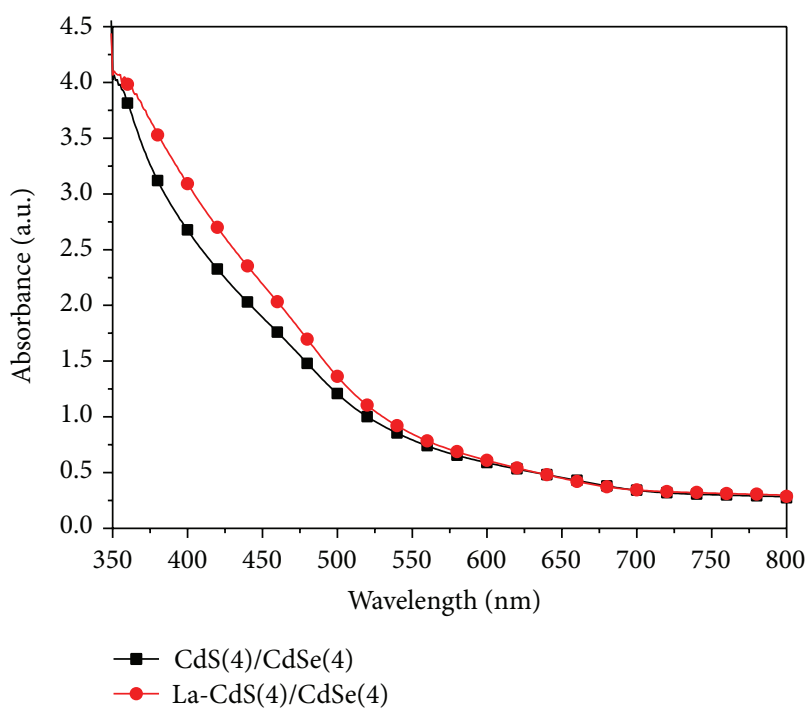

FIgURE 6: The UV-visible absorption spectra of La-doped$\mathrm{CdS}(4) / \mathrm{CdSe}(4)$ and $\mathrm{CdS}(4) / \mathrm{CdSe}(4)$.

To confirm that doped quantum dots can change the energy level of quantum dots, we have performed the ultraviolet photoelectron spectroscopy test to ascertain the top of valence band of quantum dots. Quantum dots band gap can be obtained by utilizing the absorption spectrum function: $(\alpha h v)^{2}=h v-E_{g}$ ( $\alpha$ is absorption coefficient, $E_{g}$ is band gap, and $h \nu$ is photon energy). According to the band gap and top of valence band, we can calculate the bottom of the conduction band of quantum dots. It can be known that the bottom of the conduction band of $\mathrm{TiO}_{2}$ is $4.20 \mathrm{eV}$ from the Figure le of the article "Quantum-Dot-Sensitized Solar Cell

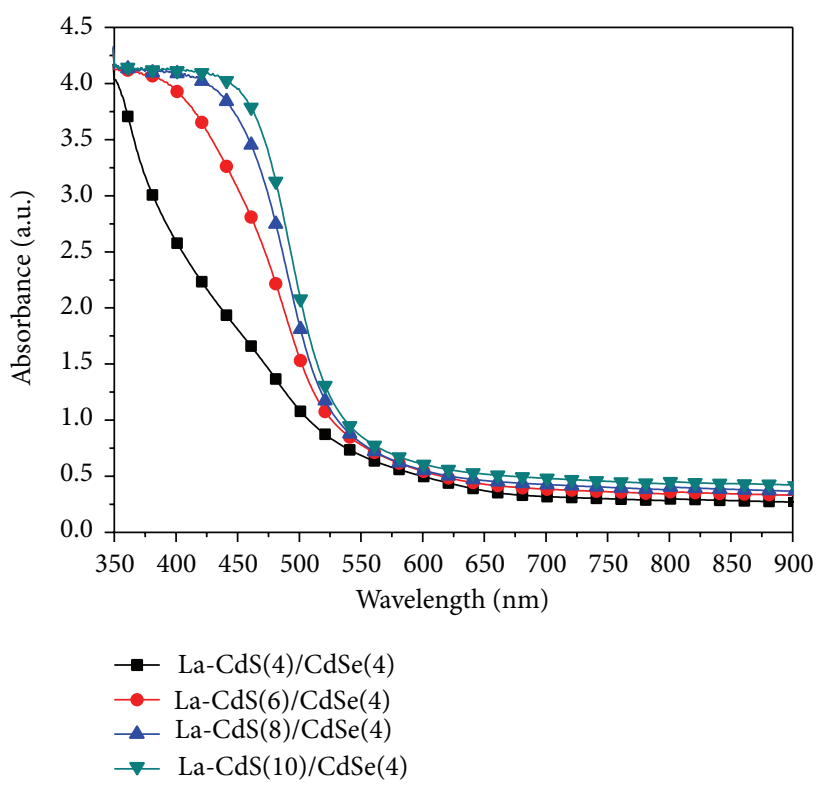

Figure 7: UV-Vis absorption spectroscopy of La-CdS/CdSe photoanode of different SILAR cycles.

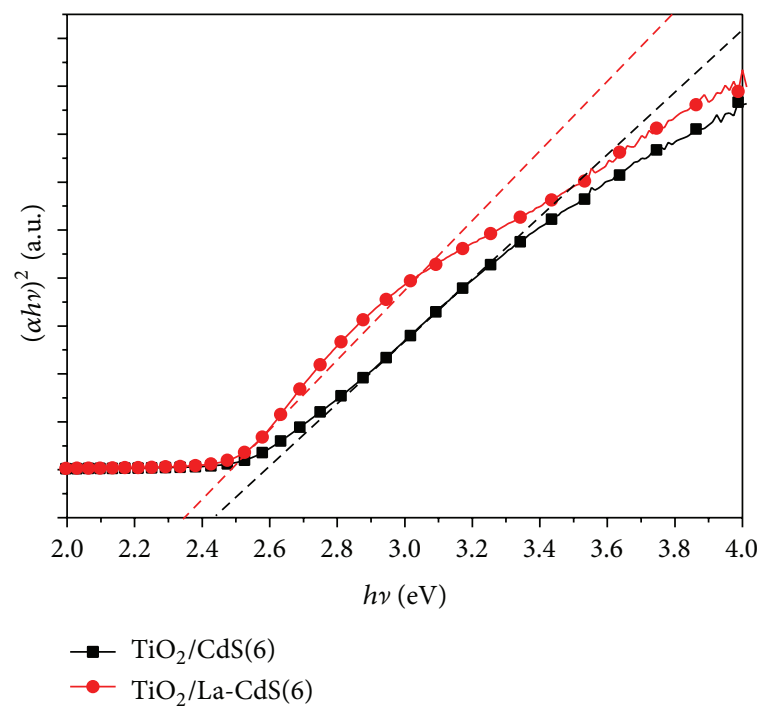

FIGURE 8: The absorption spectrum around doped CdS calculated by using $(\alpha h \nu)^{2}=h \nu-E_{g}$.

with Unprecedentedly High Photocurrent" published by Lee et al. [3].

Known from the tangent at photon energy axial intercept in Figure 8, the band gaps of $\mathrm{TiO}_{2} / \mathrm{CdS}(6)$ and $\mathrm{TiO}_{2} / \mathrm{La}-$ $\mathrm{CdS}(6)$ are $2.44 \mathrm{eV}$ and $2.35 \mathrm{eV}$, respectively. Similarly, known from the tangent at photon energy axial intercept in Figure 9, the top of valence band of $\mathrm{TiO}_{2} / \mathrm{CdS}(6)$ and that of $\mathrm{TiO}_{2} / \mathrm{La}-$ $\mathrm{CdS}(6)$ are $4.24 \mathrm{eV}$ and $4.02 \mathrm{eV}$, respectively. Consequently, we can calculate their bottoms of the conduction band which are $1.8 \mathrm{eV}$ and $1.67 \mathrm{eV}$, respectively. Figure 10 shows the corresponding energy level diagram of La-doped CdS. The band gap of CdS quantum dot becomes narrow; meanwhile, 


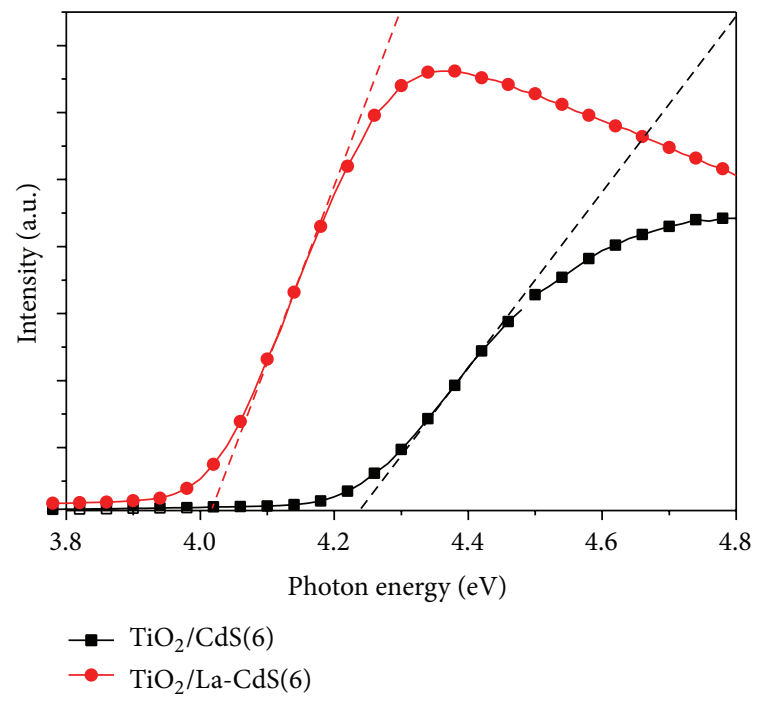

FIGURE 9: The ultraviolet photoelectron spectroscopy around doped CdS.

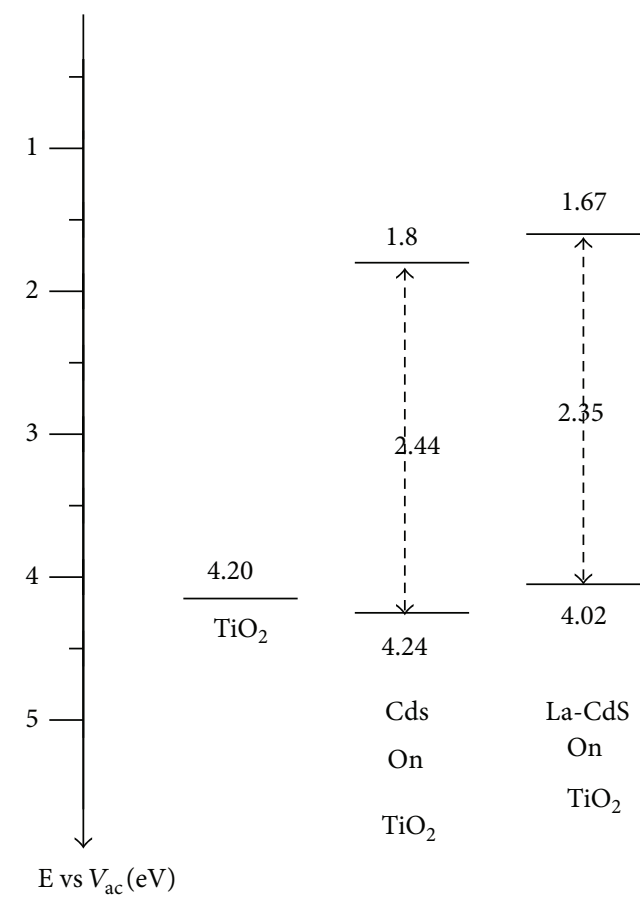

FIGURE 10: The diagram of La doping to the adjustment of CdS energy level.

its conduction band and valence band shift up. It is propitious to transport charges inside the solar cells and reduce recombination of electrons and holes, which will cause an increase of photocurrent and consequently a rise of PCE. This is consistent with experimental results.

Figure 11 shows IPCE curves of La-doped-CdS(6)/ $\mathrm{CdSe}(4)$ and $\mathrm{CdS}(8) / \mathrm{CdSe}(4)$ QDCSCs. According to the previous research of our group [14], when the cycles of CdS are 8, the efficiency of CdS/CdSe QDCSCs reach

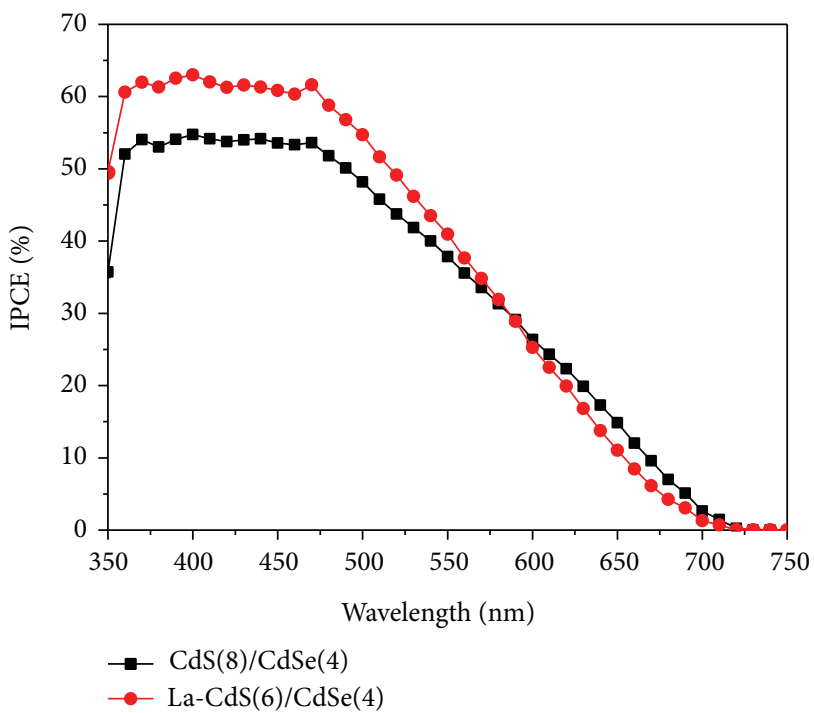

FIGURE 11: IPCE curves of La-doped-CdS(6)/CdSe(4) and CdS(8)/ CdSe(4) QDCSCs.

the maximum value. Therefore, we chose La-doped$\mathrm{CdS}(6) / \mathrm{CdSe}(4)$ and $\mathrm{CdS}(8) / \mathrm{CdSe}(4)$ to compare with each other. When the wavelength is in the range of $350-475 \mathrm{~nm}$, the maximal IPCE value is raised to $63 \%$ of La-doped solar cells while the undoped value is $55 \%$. In addition, compared with the undoped IPEC value in the wavelength range of $475-550 \mathrm{~nm}$, the La-doped IPCE value is still a little higher. It is consistent with the above corresponding absorption spectrum. We can see a slightly lowered La-doped IPCE value in the wavelength of $550-700 \mathrm{~nm}$. The reason is that the carreries generated in long wavelength do not effectively transfer to the external circuit.

\section{Conclusion}

In summary, the rare earth materials La-doped-CdS/CdSe QDCSCs were prepared for the first time using SILAR method. The dopants La in solar cells can help to increase the short circuit current. When La doping ratio was $1: 50$, the efficiency of La-doped-CdS(6)/CdSe(4) solar cells reached the maximum value $(\eta=0.70 \%)$. In the end, we systematically analyzed the influence of doped quantum dots sensitizer on the performance of CdS/CdSe QDCSCs and the charge transport mechanism inside solar cells. Namely, after La doping of quantum dots, its band gap become narrow, and conduction band and valence band shift up. It was conducive to the transmission of charges inside solar cells, increase of photocurrent, and consequently improvement of PCE. Our work offers a new direction for improving efficiencies of quantum dot sensitized solar cells.

\section{Conflict of Interests}

The authors declare that there is no conflict of interests regarding the publication of this paper. 


\section{Acknowledgments}

This work was partially supported by Key Project of Beijing Natural Science Foundation (3131001), Key Project of Natural Science Foundation of China (91233201 and 61376057), Key Project of Beijing Education Committee Science \& Technology Plan (KZ201211232040), State 863 Plan of MOST of China (2011AA050527), Beijing National Laboratory for Molecular Sciences (BNLMS2012-21), State Key Laboratory of Solid State Microstructures of Nanjing University (M27019), State Key Laboratory for New Ceramic and Fine Processing of Tsinghua University (KF1210), Key Laboratory for Renewable Energy and Gas Hydrate of Chinese Academy of Sciences (y207ka1001), Beijing Key Laboratory for Sensors of BISTU (KF20141077207 and KF20141077208), and Beijing Key Laboratory for photoelectrical measurement of BISTU (GDKF2013005).

\section{References}

[1] G. Zhu, Z. Cheng, T. Lv, L. Pan, Q. Zhao, and Z. Sun, "Zn-doped nanocrystalline $\mathrm{TiO}_{2}$ films for CdS quantum dot sensitized solar cells," Nanoscale, vol. 2, no. 7, pp. 1229-1232, 2010.

[2] W. Lee, W.-C. Kwak, S. K. Min et al., "Spectral broadening in quantum dots-sensitized photoelectrochemical solar cells based on CdSe and Mg-doped CdSe nanocrystals," Electrochemistry Communications, vol. 10, no. 11, pp. 1699-1702, 2008.

[3] J.-W. Lee, D.-Y. Son, T. K. Ahn et al., "Quantum-dot-sensitized solar cell with unprecedentedly high photocurrent," Scientific Reports, vol. 3, article 1050, 2013.

[4] Z. Huang, X. Zou, and H. Zhou, "A strategy to achieve superior photocurrent by $\mathrm{Cu}$-doped quantum dot sensitized solar cells," Materials Letters, vol. 95, pp. 139-141, 2013.

[5] L. Li, X. Zou, H. Zhou, and G. Teng, "Cu-doped-CdS/Indoped-CdS cosensitized quantum dot solar cells," Journal of Nanomaterials, vol. 2014, Article ID 314386, 8 pages, 2014.

[6] L. C.-K. Liau and C.-C. Lin, "Semiconductor characterization of $\mathrm{Cr}^{3+}$-doped titania electrodes with p-n homojunction devices," Thin Solid Films, vol. 516, no. 8, pp. 1998-2002, 2008.

[7] L. C.-K. Liau and C.-C. Lin, "Fabrication and characterization of $\mathrm{Fe}^{3+}$-doped titania semiconductor electrodes with $\mathrm{p}$-n homojunction devices," Applied Surface Science, vol. 253, no. 21, pp. 8798-8801, 2007.

[8] J. Wu, G. Xie, J. Lin, Z. Lan, M. Huang, and Y. Huang, "Enhancing photoelectrical performance of dye-sensitized solar cell by doping with europium-doped yttria rare-earth oxide," Journal of Power Sources, vol. 195, no. 19, pp. 6937-6940, 2010.

[9] H. Hafez, J. Wu, Z. Lan et al., "Erratum: Enhancing the photoelectrical performance of dye-sensitized solar cells using $\mathrm{TiO}_{2}: \mathrm{Eu}^{3+}$ nanorods," Nanotechnology, vol. 21, no. 45, Article ID 459801, pp. 415201-415206, 2010.

[10] J. Wu, J. Wang, J. Lin et al., "Enhancement of the photovoltaic performance of dye-sensitized solar cells by doping $\mathrm{Y}_{0.78} \mathrm{Yb}_{0.20} \mathrm{Er}_{0.02} \mathrm{~F}_{3}$ in the photoanode," Advanced Energy Materials, vol. 2, no. 1, pp. 78-81, 2012.

[11] J. Wu, J. Wang, J. Lin et al., "Dual functions of $\mathrm{YF}_{3}: \mathrm{Eu}^{3+}$ for improving photovoltaic performance of dye-sensitized solar cells," Scientific Reports, vol. 3, p. 2058, 2013.

[12] P. K. Santra and P. V. Kamat, "Mn-doped quantum dot sensitized solar cells: a strategy to boost efficiency over 5\%," Journal of the American Chemical Society, vol. 134, no. 5, pp. 2508-2511, 2012.
[13] Y. L. Lee, C. F. Chi, and S. Y. Liau, "CdS/CdSe Co-Sensitized $\mathrm{TiO}_{2}$ photoelectrode for efficient hydrogen generation in a photoelectrochemical cell," Chemistry of Materials, vol. 22, no. 3, pp. 922-927, 2010.

[14] X. Zou, S. He, G. Teng, and C. Zhao, "Performance study of CdS/Co-doped-CdSe quantum dot sensitized solar cells," Journal of Nanomaterials, vol. 2014, Article ID 818160, 6 pages, 2014. 

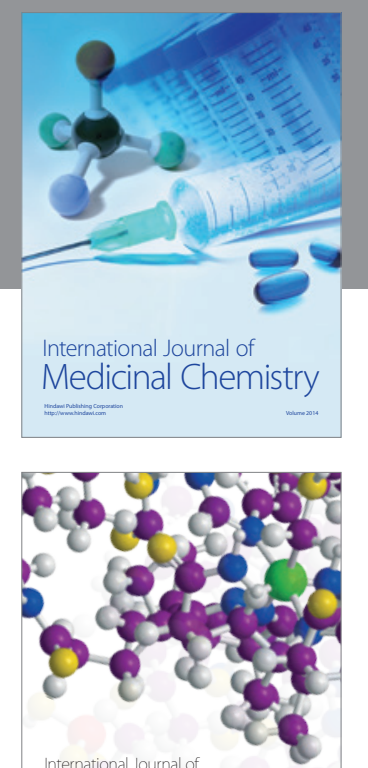

\section{Carbohydrate} Chemistry

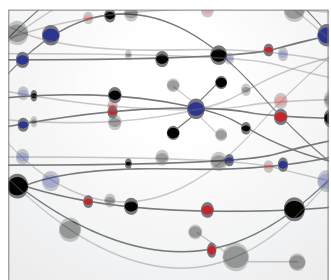

The Scientific World Journal
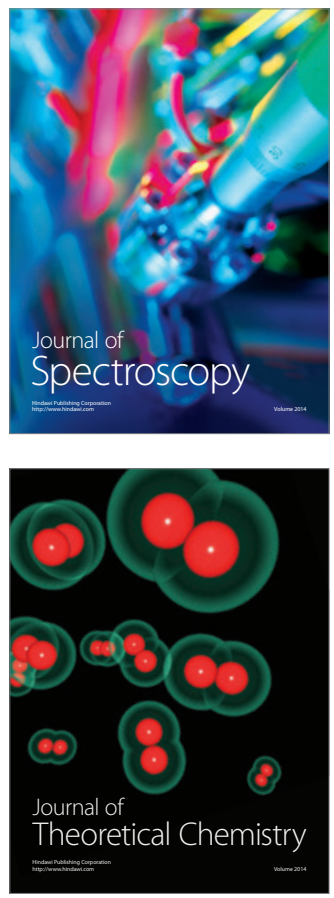
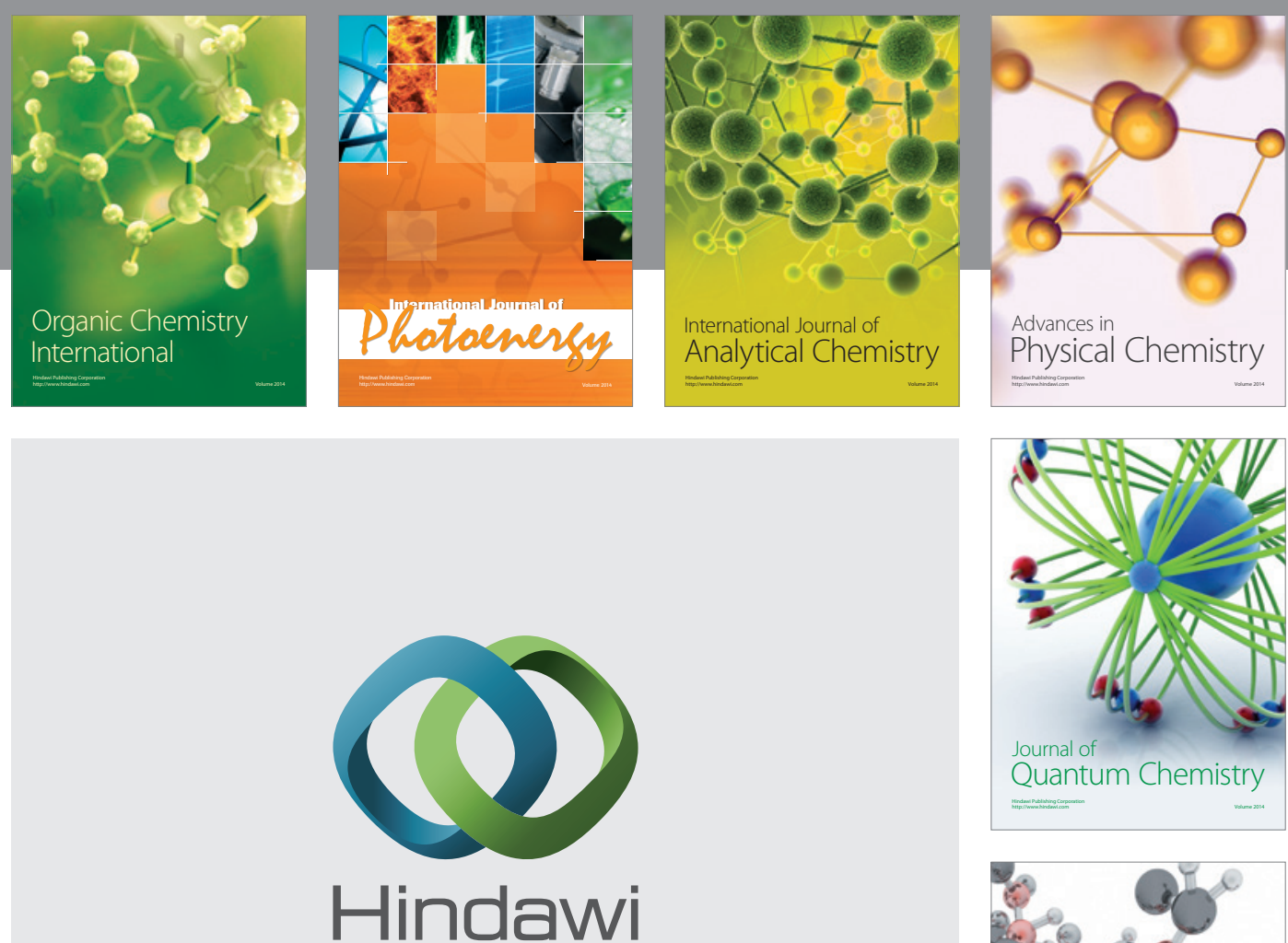

Submit your manuscripts at

http://www.hindawi.com

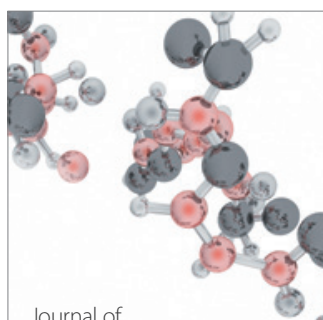

Analytical Methods

in Chemistry

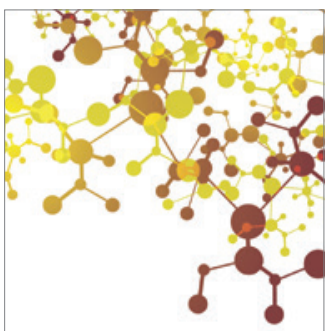

Journal of

Applied Chemistry

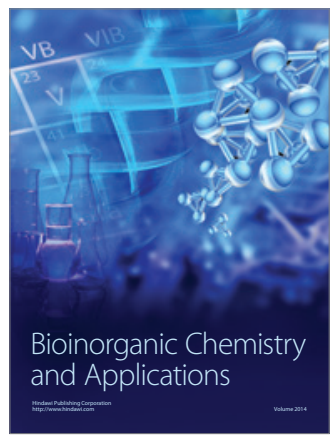

Inorganic Chemistry
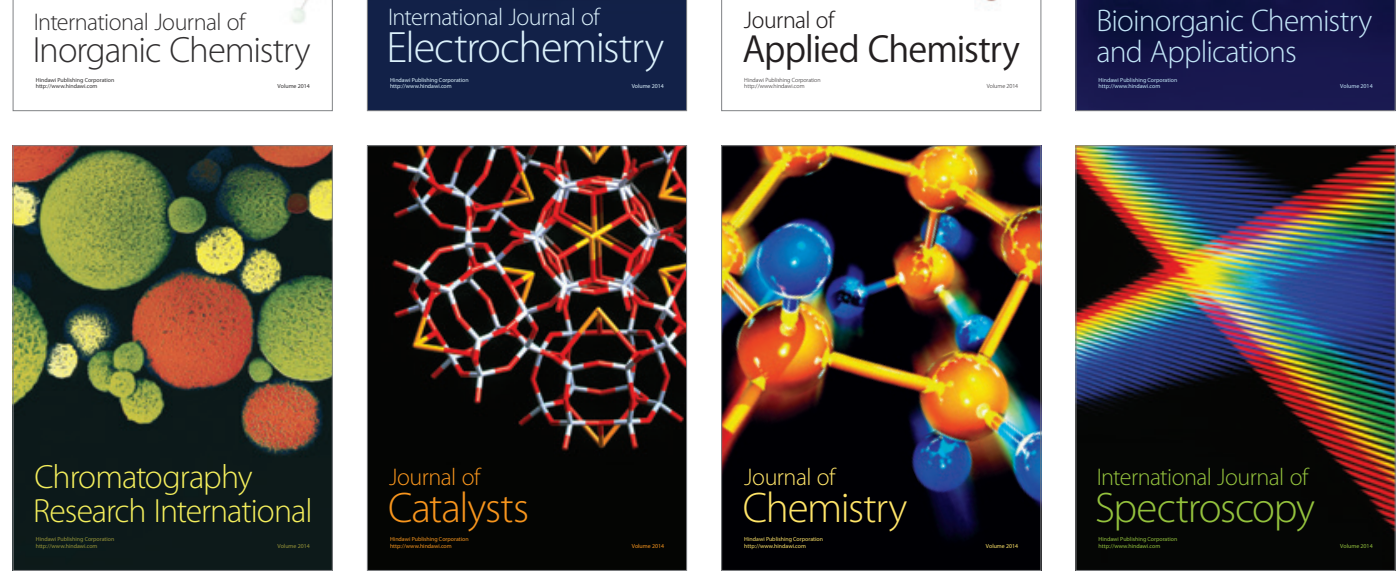